Research Article

\title{
Dynamic Modeling and Analysis of a Mine Hoisting System with Constant Length and Variable Length
}

\author{
Guoying Wang, ${ }^{1}$ Xingming Xiao $\mathbb{D}{ }^{1}$ and Yunlong Liu $\mathbb{D}^{2,3}$ \\ ${ }^{1}$ School of Mechatronic Engineering, China University of Mining and Technology, Xuzhou 221116, China \\ ${ }^{2}$ College of Information and Control Engineering, Weifang University, Weifang 261061, China \\ ${ }^{3}$ School of Electrical and Electronic, Engineering, University of Adelaide, Adelaide, SA 5005, Australia \\ Correspondence should be addressed to Xingming Xiao; xxm_cumt@126.com and Yunlong Liu; fhylren@163.com
}

Received 13 May 2019; Accepted 29 August 2019; Published 25 September 2019

Academic Editor: Jose A. Lozano-Galant

Copyright (c) 2019 Guoying Wang et al. This is an open access article distributed under the Creative Commons Attribution License, which permits unrestricted use, distribution, and reproduction in any medium, provided the original work is properly cited.

A coal mine hoisting system includes two parts, one is a constant-length cable system, and the other is a variable-length cable system. In this paper, the nonlinear dynamic modeling of a coal mine hoisting system is established through Hamilton's principle. The nonlinear partial differential equations of the coal mine hoisting system are discretized into ordinary differential equations by the fourth-order Galerkin truncation. The nonlinear dynamic responses and four key kinematic and structural parameter analysis of the coal mine hoisting system in the acceleration phases, constant velocity phases, and deceleration phases are given. The results show that the axial vibration displacements of the constant-length cable are an order of magnitude smaller than that of the variable-length cable. The load has the greatest effect on the axial vibration displacement of the hoisting cable. Adversely, the speed has the least effect on the axial vibration displacement of the hoisting cable.

\section{Introduction}

The shallow coal resources are depleted. The development and utilization of ultradeep coal resources are becoming more and more important in the future [1]. Mine hoisting equipment will develop in the direction of high speed, stability, heavy load, and ultradepth [2]. As the hoisting depth is greatly increased, the nonlinear vibration responses of the hoisting cable are more and more complex. The influence of kinematic and structural parameters on the hoisting system is becoming more and more important. Therefore, the nonlinear vibration responses and the kinematic and structural parameter characteristics of the coal mine hoist are critical to improving the reliability, safety, and service life.

Many scholars have done some research on coal mine hoist [3-8]. The lateral vibration responses of the suspension rope based on sheave sway or load change are given $[3,4]$. The effect of lateral vibration of the hoisting rope on the friction transmission stability in the mine friction hoist is studied through Adams simulation and test method. The increase in lateral vibration at the head sheave increases the instability of the friction [5]. The vibration equations of the multicable driven suspension platform systems during mine construction are derived by the constrained Lagrange equations. The theoretical results are verified by the Adams software [6]. The lateral vibration equation of the guide rope for the mine hoist is established. The influence of different factors on the guide rope characteristics is analyzed. A method for installing two guide ropes under multiboundary constraints is proposed [7]. The parameter optimization criterion is proposed for the suspension rope collision phenomenon of the multirope friction hoist [8].

There are few literatures on nonlinear vibration behavior of the coal mine hoist. The kinematic and dynamic model of the mine hoisting system is similar to the elevator system or the axially moving system [9-21]. The stability problem of a nonlinear system is considered [22]. The theoretical solution for vibration of the elevator cable, where both ends are moving, is obtained by the virtual source of the waves. The finite difference analysis is used to prove the correctness of the theoretical 
solution [9]. The nonlinear vibration characteristics of the wire rope with the drum-driven elevator system are studied by the parameter expansion method. The results show that the natural frequency of the system is greatly affected by the initial condition [10]. The mathematical modeling and nonlinear dynamics with finite amplitude of the elastic suspension cable are given $[11,12]$. Based on the energy method, the theoretical model for the coupled vibration response of the elevator system is established, and the model is verified by the experiments [13]. Mechanical and electrical models of the elevator system driven for the permanent magnet synchronous motor are established. The numerical simulation is carried out by the sliding mode controller to verify the robustness and good tracking control performance [14]. The nonlinear controller is used to stabilize the sway with the wire rope by Lyapunov theory [15]. The Lagrange method proposed the motion control equation of wire rope with the drum-driven elevator system. The frequency-amplitude relationship of the nonlinear vibration for the elevator rope is analyzed [16]. The autoresonance characteristics of the lateral vibration in the elevator time-varying rope and the initial boundary value of its lateral displacement due to boundary excitation are studied $[17,18]$. The vertical vibration of the elevator car prompted by the torque ripple effect in the elevator system is studied. The vibration frequency of the elevator car is close to the vibration frequency generated by the machine by approaching the natural frequency [19]. A proportional model is established to predict linear transverse dynamics of the time-varying rope for the elevator system. A new model is derived to count natural frequency, mode shape, and vibration response of the stationary elevator and composite cable [20,21] A control approach for a nonlinear system is proposed [23].

Few researchers have researched the dynamic behavior and kinematic and structural parameter analysis of a mine hoisting system with constant length and variable length. The coal mine hoist is primarily subject to axial excitation of its parameters without being externally motivated. In this paper, the nonlinear vibration equations of coal mine hoisting system are obtained through Hamilton's principle. The fourth-order Galerkin truncation is used to discretize the vibration equations of the coal mine hoisting system. The nonlinear vibration behaviors and key kinematic and parameter characteristics of the hoisting system during the lifting or lowering process are analyzed.

The rest of paper is organized as follows. In Section 2, the vibration mathematical model of the coal mine hoisting system are obtained and discretized. In Section 3, the nonlinear vibration behaviors and key parameter characteristics of the hoisting system are analyzed. In Section 4, the conclusions are given.

\section{The Mathematical Model of a Coal Mine Hoisting System}

2.1. Characterization of the Mathematical Model. A coal mine hoisting system consists of two parts, one is a constant-length cable system, and the other is a variable-length cable system. The constant-length cable system and the

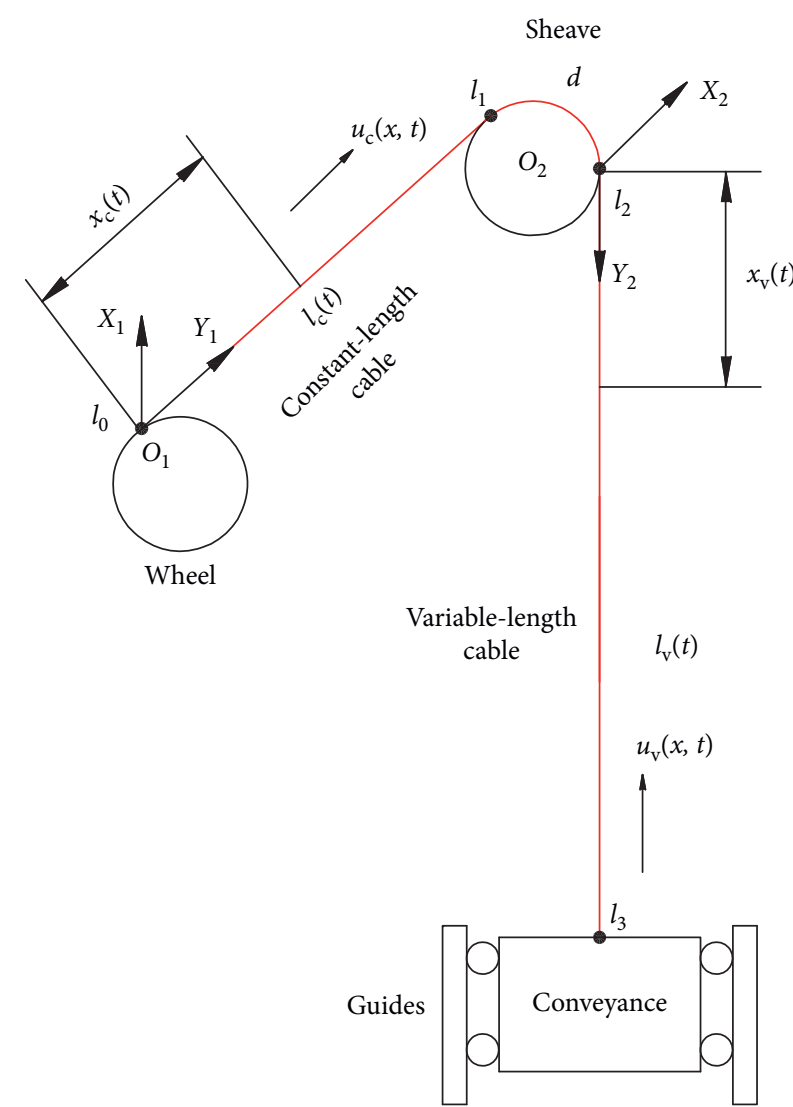

Figure 1: The model of a coal mine hoisting system.

variable-length cable system are coupled at the sheave. The model is shown in Figure 1. A coal mine hoist structure includes a wheel, constant-length cable, sheave, variablelength cable, conveyance, and guides. In this paper, the contact point between the wheel and constant-length cable is reference coordinates $O_{1} X_{1} Y_{1}$. The contact point between the sheave and variable-length cable is reference coordinates $\mathrm{O}_{2} \mathrm{X}_{2} Y_{2}$.

$l_{0}, l_{1}, l_{2}$, and $l_{3}$ are denoted as the contact point of the constant-length cable and the wheel, contact point of the constant-length cable and the sheave, contact point of the variable-length cable and the sheave, and contact point of the variable-length cable and the conveyance, respectively.

In this paper, the modeling is based on the assumptions as follows:

(1) The hoisting cable is uniform and continuous

(2) The Young's modulus, mass per unit length, and cross-sectional area of the hoisting cable remain invariant

(3) The slip line during operation is ignored

(4) The torsional and transverse vibration responses of the hoisting cable are ignored

(5) The elastic displacement due to axial vibration is greatly smaller than the length of hoisting cable

The kinetic energy of the coal mine hoisting system is as follows: 


$$
\begin{aligned}
E_{\mathrm{k}}= & \frac{1}{2} \rho \int_{l_{0}}^{l_{1}}\left(V(t)+\frac{\partial u_{\mathrm{c}}(x, t)}{\partial t}+V(t) \frac{\partial u_{\mathrm{c}}(x, t)}{\partial x}\right)^{2} d x_{\mathrm{c}} \\
& +\frac{1}{2} \frac{J}{R^{2}}\left(V(t)+\frac{\partial u_{\mathrm{c}}\left(l_{1}, t\right)}{\partial t}+V(t) \frac{\partial u_{\mathrm{c}}\left(l_{1}, t\right)}{\partial x}\right)^{2} \\
& +\frac{1}{2} \rho \int_{l_{2}}^{l_{3}}\left(V(t)+\frac{\partial u_{\mathrm{v}}(x, t)}{\partial t}+V(t) \frac{\partial u_{\mathrm{v}}(x, t)}{\partial x}\right)^{2} d x_{\mathrm{v}} \\
& +\frac{1}{2} m\left(V(t)+\frac{\partial u_{\mathrm{v}}\left(l_{3}, t\right)}{\partial t}+V(t) \frac{\partial u_{\mathrm{v}}\left(l_{3}, t\right)}{\partial x}\right)^{2},
\end{aligned}
$$

where $\rho$ is mass per unit length of the hoisting cable, $m$ is the conveyance mass, $V(t)$ is the hoisting speed of coal mine hoist, $J$ is the inertia moment of the sheave, and $R$ is the radius of the sheave. $u(x, t)$ is the axial vibration displacements of the hoisting cable in $x$ position. The subscript " $c$ " represents the constant-length cable, and the subscript "v" represents the variable-length cable.

The elastic potential energy of the coal mine hoisting system is as follows:

$$
\begin{aligned}
E_{\mathrm{p}}= & \int_{l_{0}}^{l_{1}} T_{\mathrm{c}} \frac{\partial u_{\mathrm{c}}(x, t)}{\partial x} d x_{\mathrm{c}} \\
& +\frac{1}{2} E S \int_{l_{0}}^{l_{1}}\left(\frac{\partial u_{\mathrm{c}}(x, t)}{\partial x}\right)^{2} d x_{\mathrm{c}} \\
& +\int_{l_{2}}^{l_{3}} T_{\mathrm{v}} \frac{\partial u_{\mathrm{v}}(x, t)}{\partial x} d x_{\mathrm{v}} \\
& +\frac{1}{2} E S \int_{l_{2}}^{l_{3}}\left(\frac{\partial u_{\mathrm{v}}(x, t)}{\partial x}\right)^{2} d x_{\mathrm{v}},
\end{aligned}
$$

where $E$ is Young's modulus of the hoisting cable, $S$ is the cross-sectional area of the hoisting cable, $T_{\mathrm{c}}$ is the static tension of the constant-length cable, and $T_{\mathrm{v}}$ is the static tension of the variable-length cable.

The static tension $T_{\mathrm{c}}$ and $T_{\mathrm{v}}$ are given as follows:

$$
\begin{aligned}
& T_{\mathrm{c}}=m g+\rho g l_{\mathrm{v}}(t)-\rho g\left(l_{\mathrm{c}}-x_{\mathrm{c}}\right) \sin (\theta), \\
& T_{\mathrm{v}}=m g+\rho g l_{\mathrm{v}}(t)-\rho g x_{\mathrm{v}},
\end{aligned}
$$

where $\theta$ is the angle of the constant-length cable and the horizontal plane, $l_{\mathrm{c}}$ is the length of the constant-length cable, $l_{\mathrm{v}}(t)$ is the length of the variable-length cable, and $g$ is gravity acceleration.

The gravitational potential energy of coal mine hoisting system is as follows:

$$
\begin{aligned}
E_{\mathrm{g}}= & -\int_{l_{0}}^{l_{1}} \rho g \sin (\theta) u_{\mathrm{c}}(x, t) d x_{\mathrm{c}} \\
& -\int_{l_{2}}^{l_{3}} \rho g u_{\mathrm{v}}(x, t) d x_{\mathrm{v}}-m g u_{\mathrm{v}}\left(l_{3}, t\right) .
\end{aligned}
$$

During the movement of coal mine hoist, the hoisting cable and the sheave have sliding friction. The virtual work of the coal mine hoisting system is as follows:

$$
\delta W=-c_{\mathrm{f}}\left(V(t)+\frac{\partial u_{\mathrm{c}}\left(l_{1}, t\right)}{\partial t}\right) \delta u_{\mathrm{c}}\left(l_{1}, t\right),
$$

where $c_{\mathrm{f}}$ is the friction coefficient between the hoisting cable and the sheave.

The initial boundary condition of the coal mine hoisting system is as follows:

$$
\begin{aligned}
u\left(l_{0}, t\right) & =0, \\
\frac{\partial u\left(l_{0}, t\right)}{\partial t} & =0 .
\end{aligned}
$$

Through Hamilton's principle, the motion of coal mine hoisting system between initial time $t_{1}$ and final time $t_{2}$ is as follows:

$$
\int_{t_{1}}^{t_{2}}\left(\delta E_{\mathrm{k}}-\delta E_{\mathrm{p}}-\delta E_{\mathrm{g}}\right) d t+\int_{t_{1}}^{t_{2}} \delta W d t=0
$$

According to Equation (7), the axial vibration equations of the hoisting cable are obtained as follows:

$$
\begin{gathered}
\rho\left(\frac{\partial u_{\mathrm{c}}^{2}(x, t)}{\partial t^{2}}+2 V(t) \frac{\partial u_{\mathrm{c}}^{2}(x, t)}{\partial x \partial t}+a \frac{\partial u_{\mathrm{c}}(x, t)}{\partial x}\right. \\
\left.+(V(t))^{2} \frac{\partial u_{\mathrm{c}}^{2}(x, t)}{\partial x^{2}}+a\right) \\
-\frac{\partial T_{\mathrm{c}}(x, t)}{\partial x}-E S \frac{\partial u_{\mathrm{c}}^{2}(x, t)}{\partial x^{2}}-\rho g=0, \\
\rho\left(\frac{\partial u_{\mathrm{v}}^{2}(x, t)}{\partial t^{2}}+2 V(t) \frac{\partial u_{\mathrm{v}}^{2}(x, t)}{\partial x \partial t}+a \frac{\partial u_{\mathrm{v}}(x, t)}{\partial x}\right. \\
\left.+(V(t))^{2} \frac{\partial u_{\mathrm{v}}^{2}(x, t)}{\partial x^{2}}+a\right) \\
-\frac{\partial T_{\mathrm{v}}(x, t)}{\partial x}-E S \frac{\partial u_{\mathrm{v}}^{2}(x, t)}{\partial x^{2}}-\rho \mathrm{g}=0 .
\end{gathered}
$$

Equations (8) and (9) are the axial governing equations of the constant-length cable and the variable-length cable in coal mine hoist, respectively.

The axial vibrational displacements of the constantlength cable and the variable-length cable are coupled at the sheave. Therefore, the axial vibration displacement relationship between the constant-length cable and the variable-length cable is as follows:

$$
u_{\mathrm{c}}\left(l_{1}, t\right)=u_{\mathrm{v}}\left(l_{2}, t\right) e^{c_{\mathrm{f}} d},
$$

where $d$ is contact length between the cable and head sheave.

The boundary governing equation of the coal mine hoisting system at the sheave is given as follows: 


$$
\begin{aligned}
& \frac{J}{R^{2}}\left(\frac{\partial u_{\mathrm{c}}^{2}(x, t)}{\partial t^{2}}+2 V(t) \frac{\partial u_{\mathrm{c}}^{2}(x, t)}{\partial x \partial t}\right. \\
& \left.\quad+a \frac{\partial u_{\mathrm{c}}(x, t)}{\partial x}+(V(t))^{2} \frac{\partial u_{\mathrm{c}}^{2}(x, t)}{\partial x^{2}}+a\right)\left.\right|_{x=l_{1}} \\
& \quad+E S\left(\frac{\partial u_{\mathrm{v}}\left(l_{2}, t\right)}{\partial l_{2}}-\frac{\partial u_{\mathrm{c}}\left(l_{1}, t\right)}{\partial l_{1}}\right)+T_{\mathrm{v}}\left(l_{2}, t\right) \\
& \quad-T_{\mathrm{c}}\left(l_{1}, t\right)-c_{\mathrm{f}}\left(V(t)+\frac{\partial u_{\mathrm{c}}\left(l_{1}, t\right)}{\partial t}\right)=0
\end{aligned}
$$

The boundary governing equation of the coal mine hoisting system at conveyance is given as follows:

$$
\begin{aligned}
& m\left(\frac{\partial u_{\mathrm{v}}^{2}(x, t)}{\partial t^{2}}+2 V(t) \frac{\partial u_{\mathrm{v}}^{2}(x, t)}{\partial x \partial t}\right. \\
& \left.\quad+a \frac{\partial u_{\mathrm{v}}(x, t)}{\partial x}+(V(t))^{2} \frac{\partial u_{\mathrm{v}}^{2}(x, t)}{\partial x^{2}}+a\right)\left.\right|_{x=l_{3}} \\
& \quad+\left.E S \frac{\partial u_{\mathrm{v}}(x, t)}{\partial x}\right|_{x=l_{3}} \\
& \quad+T_{\mathrm{v}}\left(l_{3}, t\right)-m g=0 .
\end{aligned}
$$

2.2. Discretization of Mathematical Model. The purpose of discretization is to discretize the differential equations that are difficult to solve into ordinary differential equations that are easy to solve. In this paper, the spatial partial differential vibration equations are discretized into ordinary differential equations by fourth-order Galerkin truncation [24].

To facilitate the analysis of the model, an independent variable $\beta=x / l$ is defined. A domain $[0, l]$ for $x$ is transformed into a fixed domain $[0,1]$ for $\beta$. The axial vibration displacements of the constant-length cable and variable-length cable are determined as follows:

$$
\begin{aligned}
& u_{\mathrm{c}}(x, t)=u_{\mathrm{c}}(\beta, t), \\
& u_{\mathrm{v}}(x, t)=u_{\mathrm{v}}(\beta, t) .
\end{aligned}
$$

The axial vibration displacements of the constant-length cable and variable-length cable are approximated as follows:

$$
\begin{aligned}
& u_{\mathrm{c}}(\beta, t)=\sum_{i=1}^{4} \kappa_{i}(\beta) p_{i}(t), \\
& u_{\mathrm{v}}(\beta, t)=\sum_{i=1}^{4} \lambda_{i}(\beta) q_{i}(t),
\end{aligned}
$$

where $\kappa_{i}(\beta)$ and $\lambda_{i}(\beta)$ are trial functions of the constantlength cable and variable-length cable, respectively, and $p(t)$ and $q(t)$ are generalized coordinates of the constant-length cable and variable-length cable, respectively.

The trial functions $\kappa_{i}(\beta)$ and $\lambda_{i}(\beta)$ are expressed as follows:

$$
\begin{aligned}
& \kappa_{i}(\beta)=\sqrt{2} \sin \left(\frac{(2 i-1)}{2} \pi \beta\right) \quad(i=1,2, \ldots, 4), \\
& \lambda_{i}(\beta)=\sqrt{2} \sin \left(\frac{(2 i-1)}{2} \pi \beta\right) \quad(i=1,2, \ldots, 4) .
\end{aligned}
$$

By the independent variable $\beta$, the partial derivatives of the constant-length cable are as follows:

$$
\begin{aligned}
& \frac{\partial u_{\mathrm{c}}(x, t)}{\partial x}=\frac{1}{l_{\mathrm{c}}} \sum_{i=1}^{4} \frac{d \kappa_{i}(\beta)}{d \beta} p_{i}(t), \\
& \frac{\partial u_{\mathrm{c}}^{2}(x, t)}{\partial x^{2}}=\frac{1}{l_{\mathrm{c}}^{2}} \sum_{i=1}^{4} \frac{d \kappa_{i}^{2}(\beta)}{d \beta^{2}} p_{i}(t), \\
& \frac{\partial u_{\mathrm{c}}(x, t)}{\partial t}=\sum_{i=1}^{4} \kappa_{i}(\beta) \dot{p}_{i}(t), \\
& \frac{\partial u_{\mathrm{c}}^{2}(x, t)}{\partial t^{2}}=\sum_{i=1}^{4} \kappa_{i}(\beta) \ddot{p}_{i}(t), \\
& \frac{\partial u_{\mathrm{c}}(x, t)}{\partial x \partial t}=\frac{1}{l_{\mathrm{c}}} \sum_{i=1}^{4} \frac{d \kappa_{i}(\beta)}{d \beta} \dot{p}_{i}(t) .
\end{aligned}
$$

The partial derivatives of the variable-length cable are as follows:

$$
\begin{aligned}
& \frac{\partial u_{\mathrm{v}}(x, t)}{\partial x}=\frac{1}{l_{\mathrm{v}}(t)} \sum_{i=1}^{4} \frac{d \lambda_{i}(\beta)}{d \beta} q_{i}(t), \\
& \frac{\partial u_{\mathrm{v}}^{2}(x, t)}{\partial x^{2}}=\frac{1}{l_{\mathrm{v}}^{2}(t)} \sum_{i=1}^{4} \frac{d \lambda_{i}^{2}(\beta)}{d \beta^{2}} q_{i}(t), \\
& \frac{\partial u_{\mathrm{v}}(x, t)}{\partial t}=\sum_{i=1}^{4} \lambda_{i}(\beta) \dot{q}_{i}(t)-\frac{V(t) \beta}{l_{\mathrm{v}}(t)} \sum_{i=1}^{4} \frac{d \lambda_{i}(\beta)}{d \beta} q_{i}(t), \\
& \frac{\partial u_{\mathrm{v}}(x, t)}{\partial x \partial t}=\frac{1}{l_{\mathrm{v}}(t)} \sum_{i=1}^{4} \frac{d \lambda_{i}(\beta)}{d \beta} \dot{q}_{i}(t)-\frac{V(t)}{l_{\mathrm{v}}^{2}(t)} \sum_{i=1}^{4} \frac{d \lambda_{i}(\beta)}{d \beta} q_{i}(t) \\
& -\frac{V(t) \beta}{l_{\mathrm{v}}^{2}(t)} \sum_{i=1}^{4} \frac{d \lambda_{i}^{2}(\beta)}{d \beta^{2}} q_{i}(t), \\
& \frac{\partial u_{\mathrm{v}}^{2}(x, t)}{\partial t^{2}}=\sum_{i=1}^{4} \lambda_{i}(\beta) \ddot{q}_{i}(t)-\frac{2 V(t) \beta}{l_{\mathrm{v}}(t)} \sum_{i=1}^{4} \frac{d \lambda_{i}(\beta)}{d \beta} \dot{q}_{i}(t) \\
& +\left(\frac{V(t) \beta}{l_{\mathrm{v}}(t)}\right)^{2} \sum_{i=1}^{4} \frac{d \lambda_{i}^{2}(\beta)}{d \beta^{2}} q_{i}(t) \\
& +\frac{2 V^{2}(t) \beta}{l_{\mathrm{v}}^{2}(t)} \sum_{i=1}^{4} \frac{d \lambda_{i}(\beta)}{d \beta} q_{i}(t) \\
& -\frac{a \beta}{l_{\mathrm{v}}(t)} \sum_{i=1}^{4} \frac{d \lambda_{i}(\beta)}{d \beta} q_{i}(t) .
\end{aligned}
$$


The discretized differential equations of the constantlength cable and variable-length cable in coal mine hoist are given as follows:

$$
\begin{aligned}
\sum_{i=1}^{4} & \sum_{j=1}^{4}\left(\rho \delta_{i j}+\frac{J / R^{2}}{l_{\mathrm{c}}} \tau_{i j}\right) \ddot{p}_{i}(t)+\sum_{i=1}^{4} \sum_{j=1}^{4}\left(\frac{2 \rho V}{l_{\mathrm{c}}} C_{11}-\frac{c_{\mathrm{f}}}{l_{\mathrm{c}}} \tau_{i j}\right) \dot{p}_{i}(t) \\
& +\sum_{i=1}^{4} \sum_{j=1}^{4}\left(\frac{\rho a}{l_{\mathrm{c}}} C_{11}\right) p_{i}(t)+\sum_{i=1}^{4} \sum_{j=1}^{4}\left(\left(\frac{\rho V^{2}-E S}{l_{\mathrm{c}}^{2}}\right) K_{11}\right) p_{i}(t) \\
& +\sum_{j=1}^{4} \frac{\rho a}{l_{\mathrm{c}}} F_{11}+\sum_{j=1}^{4}(-1)^{j-1} \frac{\left(m+\rho l_{\mathrm{v}}(t)+J / R^{2}\right) a}{l_{\mathrm{c}}}=0, \\
\sum_{i=1}^{4} & \sum_{j=1}^{4}\left(\rho \delta_{i j}+\frac{m}{l_{\mathrm{v}}} \tau_{i j}\right) \ddot{q}_{i}(t)-\sum_{i=1}^{4} \sum_{j=1}^{4} \frac{V}{l_{\mathrm{v}}} \delta_{i j} \dot{q}_{i}(t) \\
& +\sum_{i=1}^{4} \sum_{j=1}^{4}\left(\frac{2 \rho V}{l_{\mathrm{v}}} C_{21}\right) \dot{q}_{i}(t)+\sum_{i=1}^{4} \sum_{j=1}^{4}\left(\left(\frac{\rho a}{l_{\mathrm{v}}(t)}-\frac{3 \rho V^{2}}{l_{\mathrm{v}}^{2}(t)}\right) C_{21}\right) q_{i}(t) \\
& +\sum_{i=1}^{4} \sum_{j=1}^{4}\left(\frac{\rho V^{2}}{l_{\mathrm{v}}^{2}(t)} K_{21}\right) q_{i}(t)-\sum_{i=1}^{4} \sum_{j=1}^{4}\left(\frac{E S}{l_{\mathrm{v}}^{2}(t)} K_{22}\right) q_{i}(t) \\
& -\sum_{j=1}^{4} \sum_{i=1}^{4} \frac{\tau_{i j}}{l_{\mathrm{v}}(t) e^{c_{\mathrm{f}} d}} p_{i}(t)+\sum_{j=1}^{4}\left(\frac{\rho(a+g)}{l_{\mathrm{v}}(t)} F_{21}\right) \\
& +\sum_{j=1}^{4}\left((-1)^{j-1}\left(\frac{m a}{l_{\mathrm{v}}(t)}\right)\right)=0,
\end{aligned}
$$

where

$$
\begin{aligned}
C_{11} & =\int_{0}^{1}\left(\frac{d \kappa_{i}(\beta)}{d \beta}\right) \kappa_{j}(\beta) d \beta, \\
K_{11} & =\int_{0}^{1}\left(\frac{d \kappa_{i}^{2}(\beta)}{d \beta^{2}}\right) \kappa_{j}(\beta) d \beta, \\
F_{11} & =\int_{0}^{1} \kappa_{j}(\beta) d \beta, \\
C_{21} & =\int_{0}^{1}(1-\beta)\left(\frac{d \lambda_{i}(\beta)}{d \beta}\right) \lambda_{j}(\beta) d \beta, \\
K_{21} & =\int_{0}^{1}(1-\beta)^{2}\left(\frac{d \lambda_{i}^{2}(\beta)}{d \beta^{2}}\right) \lambda_{j}(\beta) d \beta, \\
K_{22} & =\int_{0}^{1}\left(\frac{d \lambda_{i}^{2}(\beta)}{d \beta^{2}}\right) \lambda_{j}(\beta) d \beta, \\
F_{21} & =\int_{0}^{1} \lambda_{j}(\beta) d \beta, \\
\left\{\begin{array}{l}
\delta_{i j}=1, \quad i=j, \\
\delta_{i j}=-1, \quad i \neq j . \\
\delta_{i j}=0, \quad i \neq j,
\end{array}\right. &
\end{aligned}
$$

TABLe 1: The coal mine hoist parameters.

\begin{tabular}{lc}
\hline Parameters & Value \\
\hline Radius of the sheave $R(\mathrm{~m})$ & 2.45 \\
Inertia moment of the sheave $J\left(\mathrm{~kg} / \mathrm{m}^{2}\right)$ & $1.5 \times 10^{4}$ \\
Cross-sectional area of the hoisting cable $S\left(\mathrm{~m}^{2}\right)$ & $1.9 \times 10^{-3}$ \\
Young's modulus of the hoisting cable $E\left(\mathrm{~N} / \mathrm{m}^{2}\right)$ & $1.01 \times 10^{11}$ \\
Mass per unit length of the hoisting cable $\rho(\mathrm{kg} / \mathrm{m})$ & 8.6 \\
Constant length of the constant-length cable $l_{\mathrm{c}}(\mathrm{m})$ & 80 \\
Friction coefficient between the cable and sheave $c$ & 0.1 \\
Contact length between the cable and sheave $d(\mathrm{~m})$ & 3.5 \\
Angle of the constant-length cable and the horizontal & $\pi / 6$ \\
plane $\theta(\mathrm{rad})$ & 9.8 \\
Gravity acceleration $g\left(\mathrm{~m} / \mathrm{s}^{2}\right)$ &
\end{tabular}

The discretized differential equations are solved to obtain generalized coordinates $p_{i}(t)$ and $q_{i}(t)$. Inserting generalized coordinates into Equations (13) and (14), the axial vibration displacements of the constant-length cable and variablelength cable are obtained.

\section{Results and Discussion}

According to the mathematical model of the coal mine hoisting system, the real effect of the typical structural parameters on the hoister is analyzed. The coal mine hoist parameters are shown in Table 1.

The axial vibration behaviors of coal mine hoist are different from the lifting or lowering process due to the timevarying characteristics of the cable. In order to prevent misoperation, it is assumed that the load of the coal mine hoist is full in lifting and lowering. The hoisting pattern of the coal mine hoist is shown in Figure 2.

The kinematic parameters of the coal mine hoist are as follows: the coil mine depth is $1580 \mathrm{~m}$, the maximum velocity is $15 \mathrm{~m} / \mathrm{s}$, the maximum acceleration is $0.75 \mathrm{~m} / \mathrm{s}^{2}$, the hoisting time is $120 \mathrm{~s}$, and the conveyance mass is $4 \times 10^{4} \mathrm{~kg}$.

The axial vibration displacements of the hoisting cable are shown in Figures 3 and 4. From the acceleration phases to the constant velocity phases and from the constant velocity phases to the deceleration phases, the axial vibration displacements of the hoisting cable changes significantly. The length of the constant-length cable is much shorter than the variable-length cable in coal mine hoist. Therefore, the axial vibration displacements of the constant-length cable are at an order of magnitude smaller than the variable-length cable. The axial vibration characteristics of the constantlength cable in lifting and lowering are similar because the length of the constant-length cable is constant. The length of the variable-length cable is time-varying; thus, axial vibration characteristics of the variable-length cable in lifting and lowering process are different. The axial vibration frequency of variable-length cable in lifting process is greater than that in lowering process. This shows that the axial vibration of the lifting process is intense compared to the lowering process. However, the maximum axial vibration displacement of the variable-length cable in the lifting process is similar to the downward process, which occurs near the bottom of the shaft. 

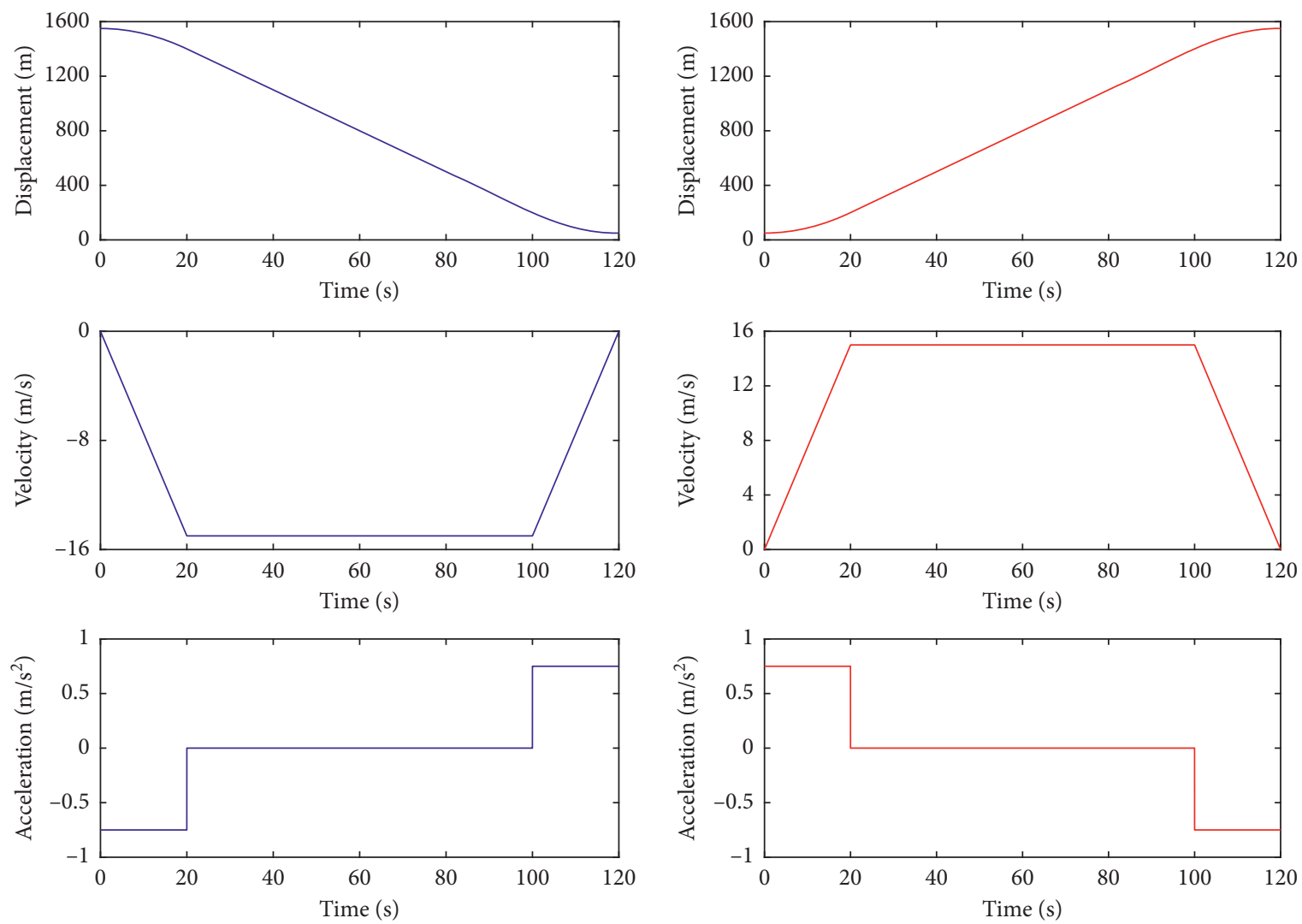

(a)

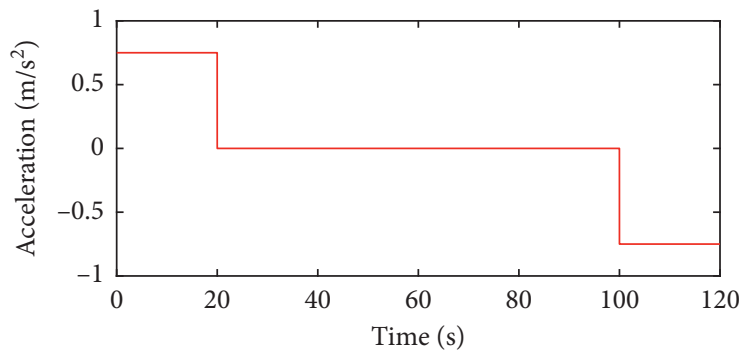

(b)

FIGURE 2: The hoisting pattern of the coal mine hoist. (a) In lifting the hoist. (b) In lowering the hoist.

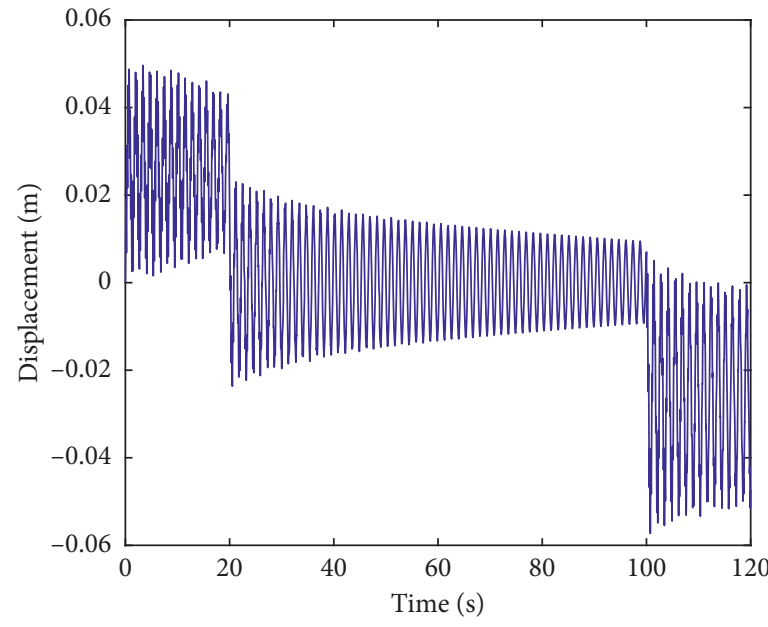

(a)

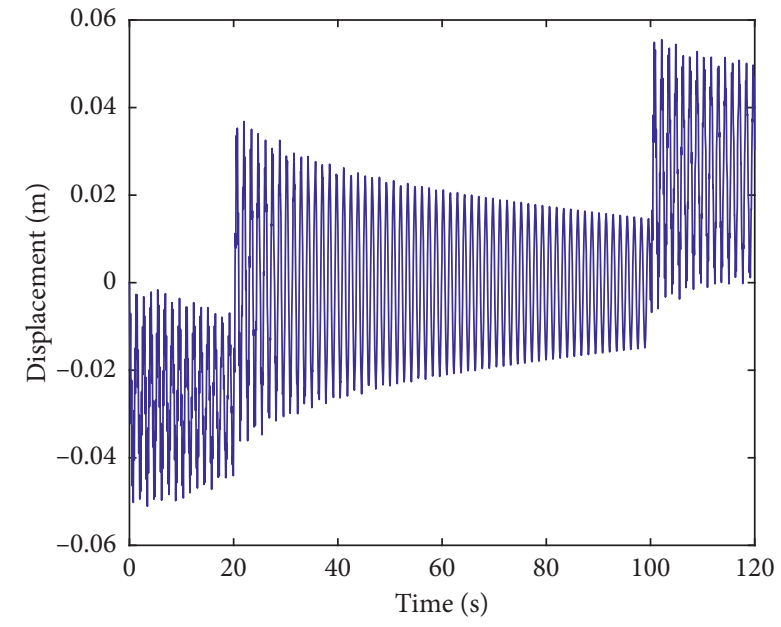

(b)

Figure 3: Axial vibration displacements of the constant-length cable at the sheave. (a) In lifting the hoist. (b) In lowering the hoist.

The coal mine hoist develops in the direction of high speed, high stability, heavy load, and ultradeep. The effects of kinematic and structural parameters such as hoisting load, hoisting height, hoisting acceleration, and hoisting velocity on the axial vibration responses of hoisting cable are not negligible. In the three operating phases of acceleration, constant velocity, and deceleration, the axial vibration responses of the hoisting cable is different. In this paper, four typical parameters of hoisting load, hoisting depth, hoisting acceleration, and hoisting velocity are discussed. The effects of four parameters on maximum axial vibration displacement of the hoisting cable in acceleration phases, constant velocity phases, and deceleration phases are analyzed. 


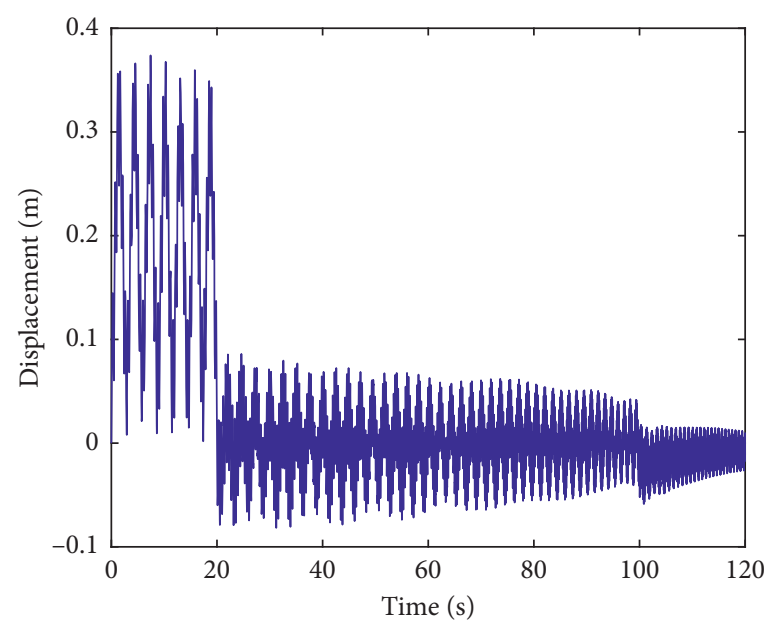

(a)

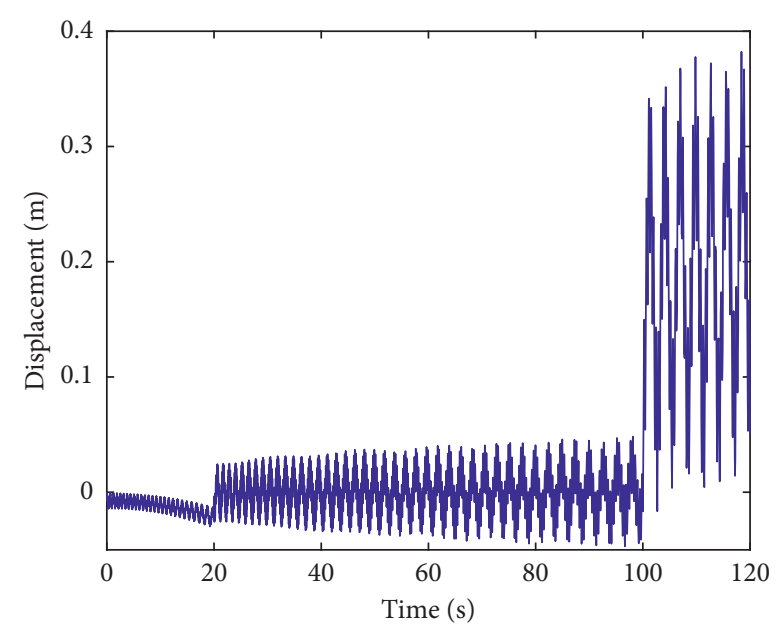

(b)

Figure 4: Axial vibration displacements of the variable-length cable at conveyance. (a) In lifting the hoist. (b) In lowering the hoist.

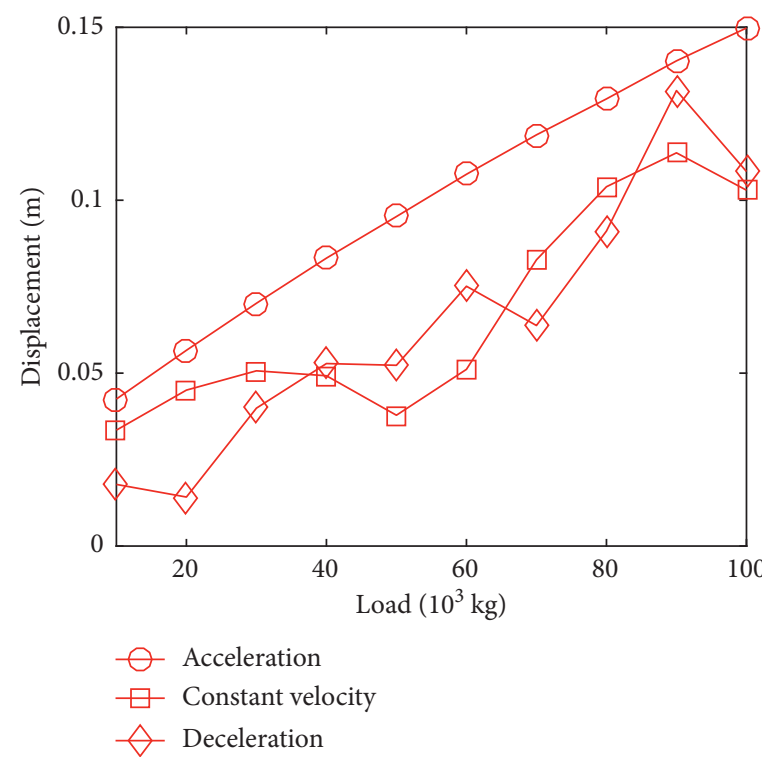

(a)

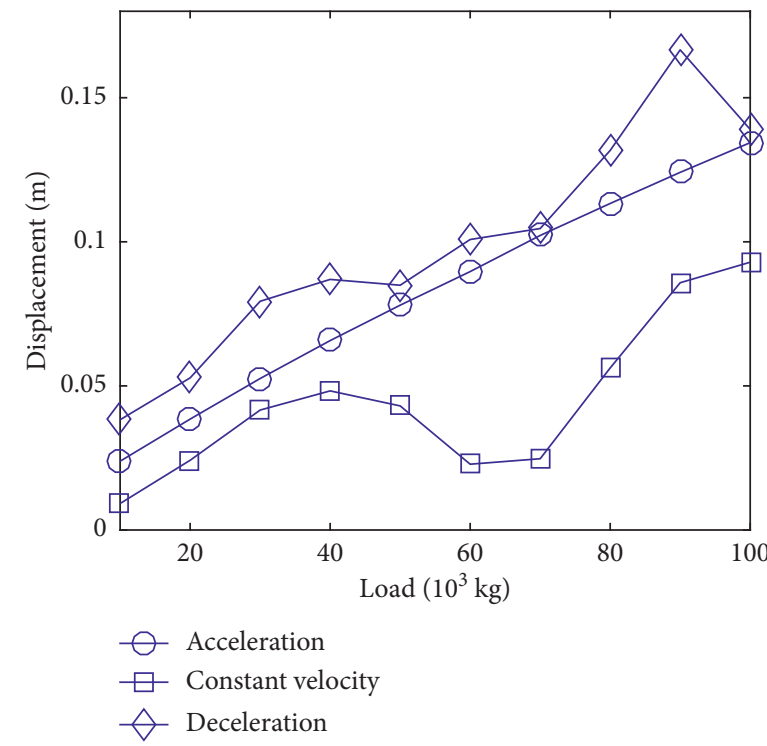

(b)

Figure 5: Maximum axial vibration displacements of the constant-length cable under different loads. (a) In lifting the hoist. (b) In lowering the hoist.

The maximum axial vibration displacements of the constant-length cable and the variable-length cable under different loads are shown in Figures 5 and 6. In the acceleration phases of coal mine hoist, the axial vibration responses of the hoisting cable are mainly affected by load. The maximum vibration displacements of the constant-length cable and variable-length cable are linearly positive correlated with loads. In the constant velocity and deceleration phases of coal mine hoist, the axial vibration behaviors of the hoisting cable are affected by the load and tension generated during the hoisting process. The maximum vibration displacements of the constant-length cable and variable-length cable are nonlinear with loads. In the lifting or lowering process of the coal mine hoist, the maximum axial vibration displacements of the hoisting cable are near the bottom of the shaft.

The maximum axial vibration displacements of the constant-length cable and the variable-length cable under different depths are shown in Figures 7 and 8. In the acceleration phases of coal mine hoist, the axial vibration responses of the hoisting cable are mainly affected by depth. The maximum vibration displacements of the constantlength cable and variable-length cable are linearly positive correlated with depths. During the constant velocity and deceleration phases of the coal mine hoist in lifting, the axial vibration responses of the hoisting cable are affected by its own tension and depth. The maximum vibration displacements have a nonlinear relationship with the depths. The 


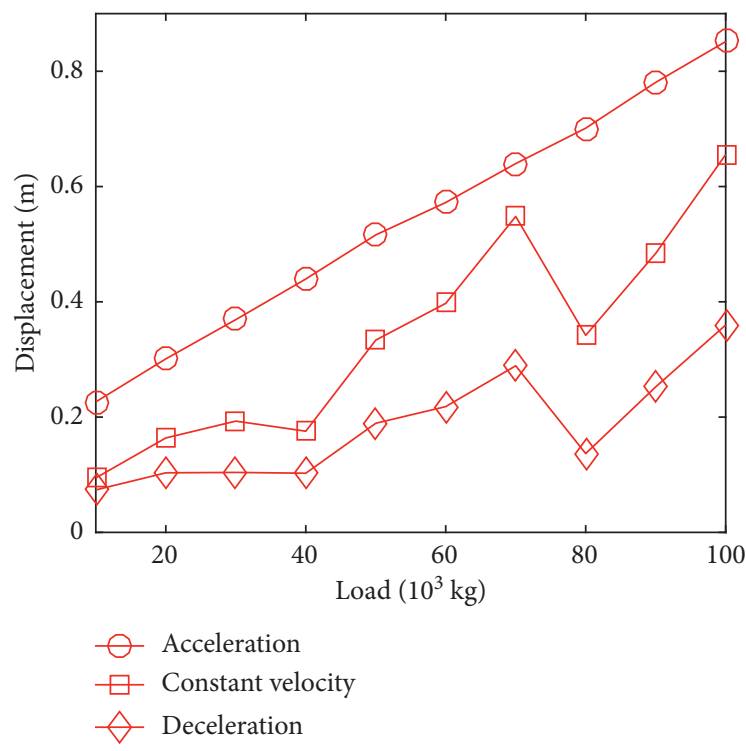

(a)

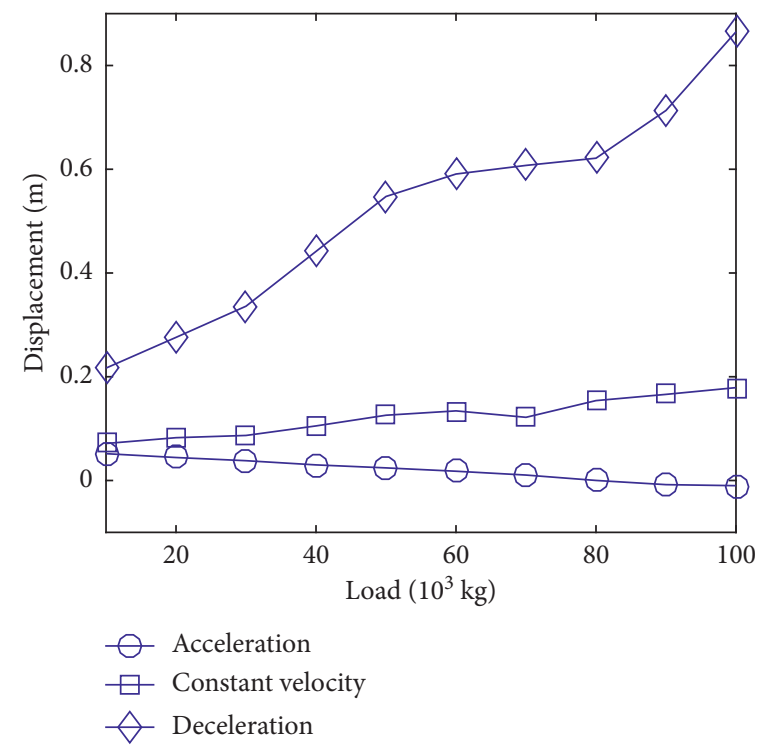

(b)

Figure 6: Maximum axial vibration displacements of the variable-length cable under different loads. (a) In lifting the hoist. (b) In lowering the hoist.

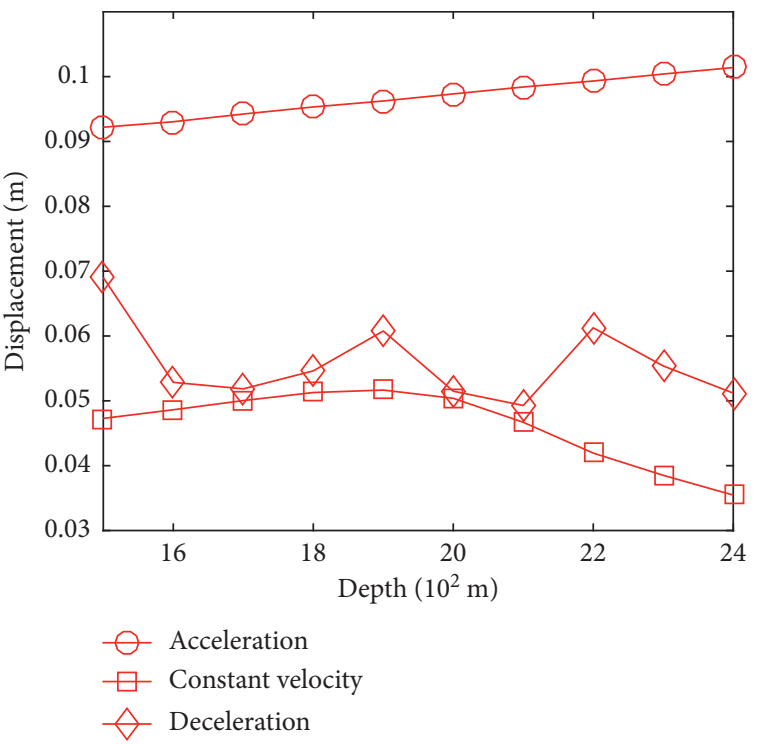

(a)

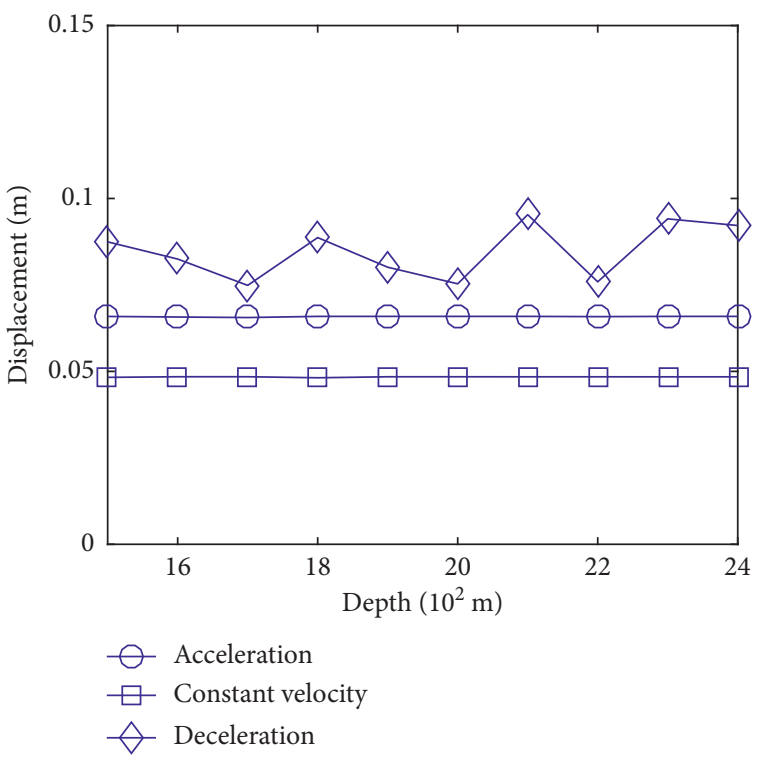

(b)

FiguRE 7: Maximum axial vibration displacements of the constant-length cable under different depths. (a) In lifting the hoist. (b) In lowering the hoist.

constant-length cable showed a downward trend, while the variable-length cable showed an upward trend. This is because a constant-length cable is of constant length and a variable-length cable is of time-varying length. When the coal mine hoister is in the lowering process, the vibration displacements of the hoisting cable in the deceleration phases are less affected by self-tension. The vibration displacements and depths of the hoisting cable are linear. However, the axial vibration displacements of the hoisting cable in deceleration phases are greatly affected by self- tension and depths. The axial vibration displacements of the hoisting cable exhibit a nonlinear change. Due to the timevarying nature of the variable-length cable, the axial vibration displacements of the variable-length cable gradually increase as the depth increases. In the lifting or lowering process of the coal mine hoist, the maximum vibration displacements of the constant-length cable are near the bottom of the shaft.

The maximum axial vibration displacements of the constant-length cable and variable-length cable under different 


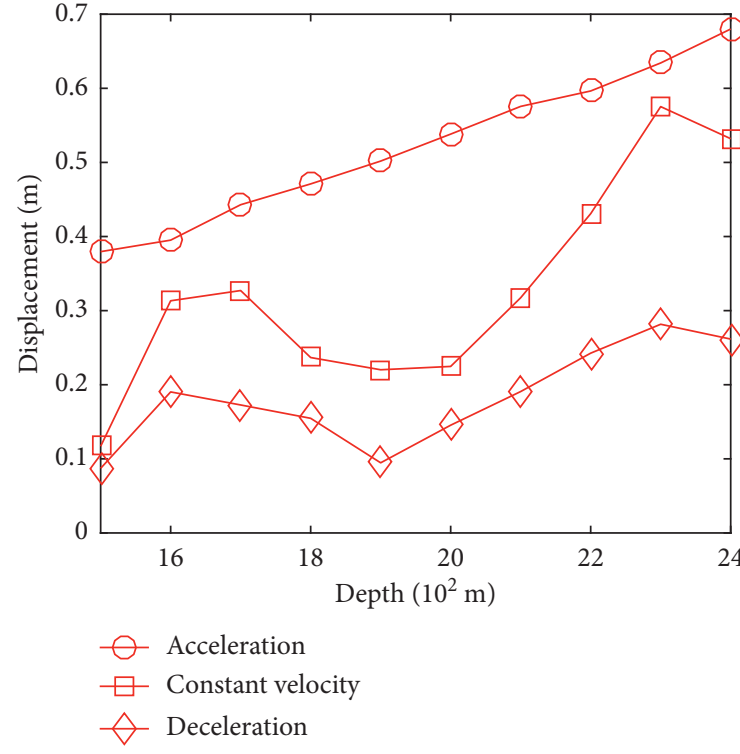

(a)

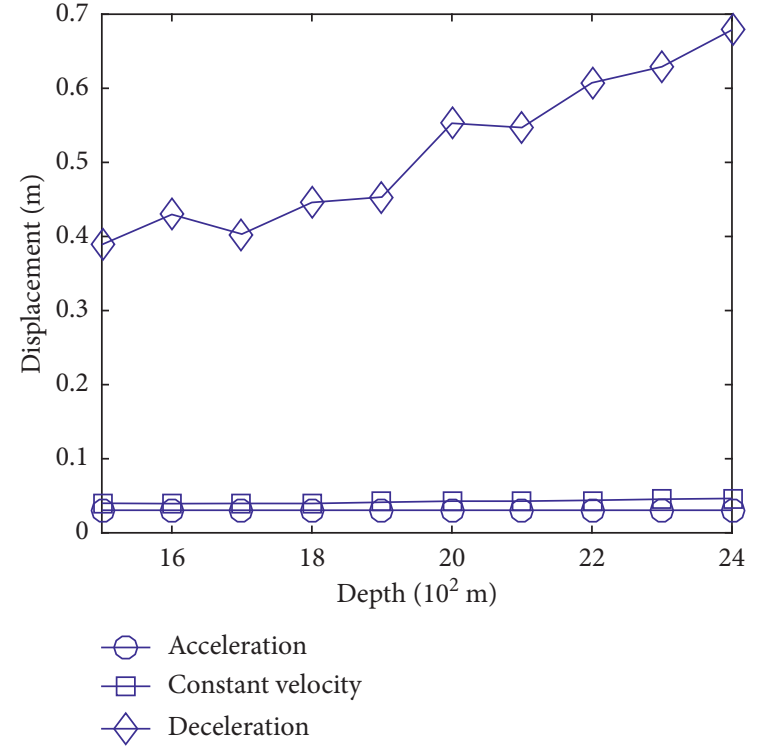

(b)

Figure 8: Maximum axial vibration displacements of the variable-length cable under different depths. (a) In lifting the hoist. (b) In lowering the hoist.

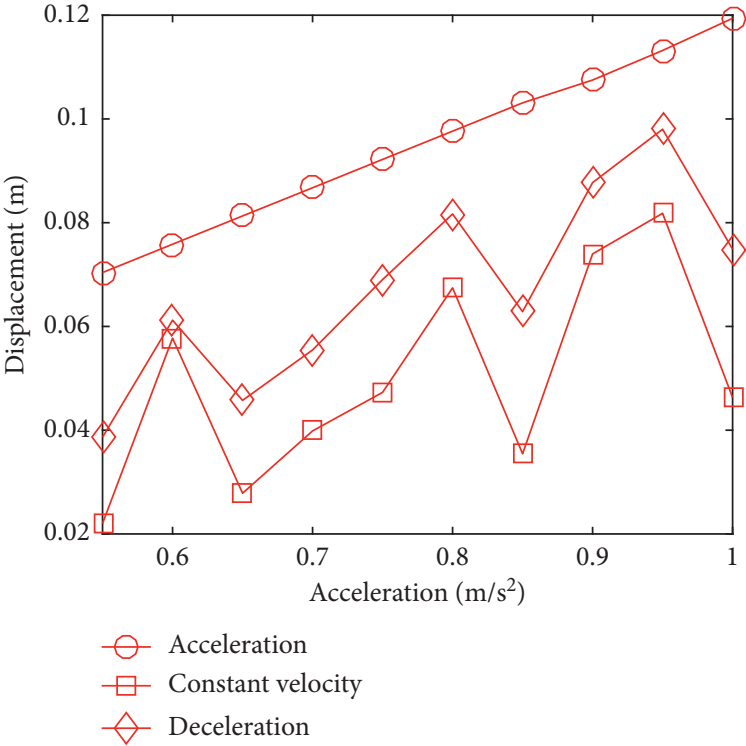

(a)

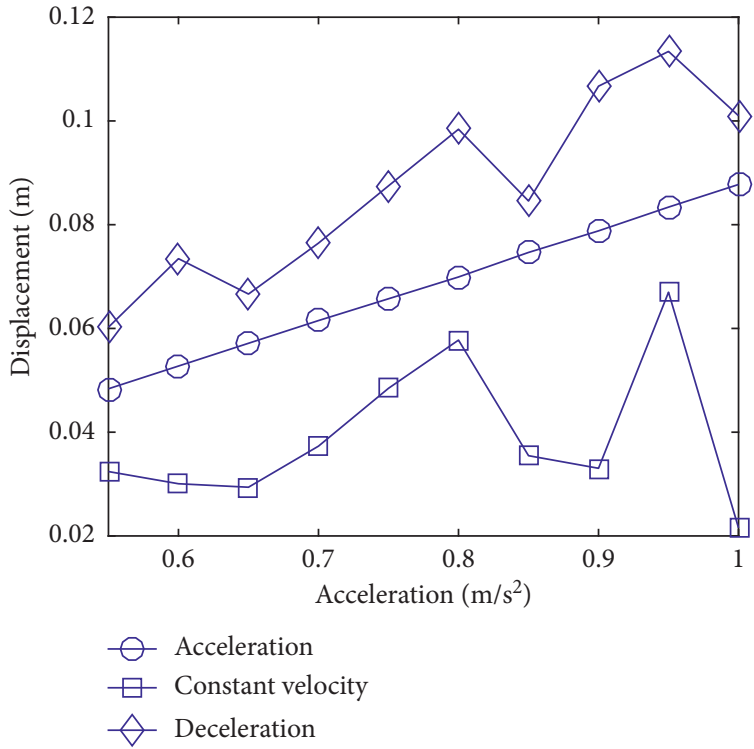

(b)

FIGURE 9: Maximum axial vibration displacements of the constant-length cable under different accelerations. (a) In lifting the hoist. (b) In lowering the hoist.

accelerations are shown in Figures 9 and 10. In the acceleration phases of coal mine hoist, the axial vibration responses of the hoisting cable are mainly affected by acceleration. The maximum vibration displacements of the constant-length cable and variable-length cable are linearly positive correlated with accelerations. In constant velocity and deceleration phases of coal mine hoist, the constant-length cable and variable-length cable are affected by the acceleration and tension generated during the hoisting process, which causes the axial vibration displacements of the hoisting cable to be nonlinear. During the lowering process of the coal mine hoist, due to the timevarying nature of the variable-length cable, the axial vibration displacements of the variable-length cable changes little in the constant velocity phase. In the lifting or lowering process of the coal mine hoist, the maximum displacements of the axial vibration of hoisting cable are near the bottom of the shaft.

The maximum axial vibration displacements of the constant-length cable and variable-length cable under 


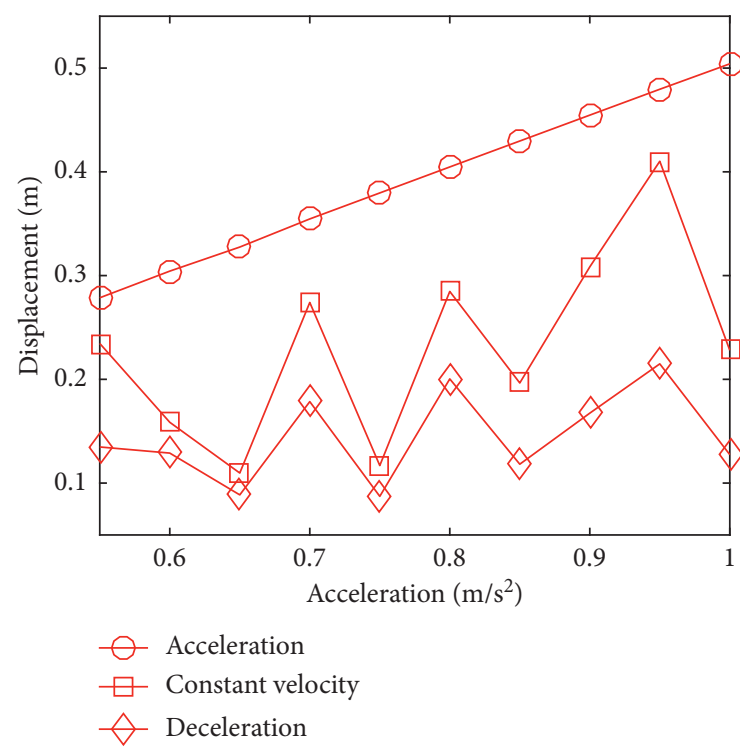

(a)

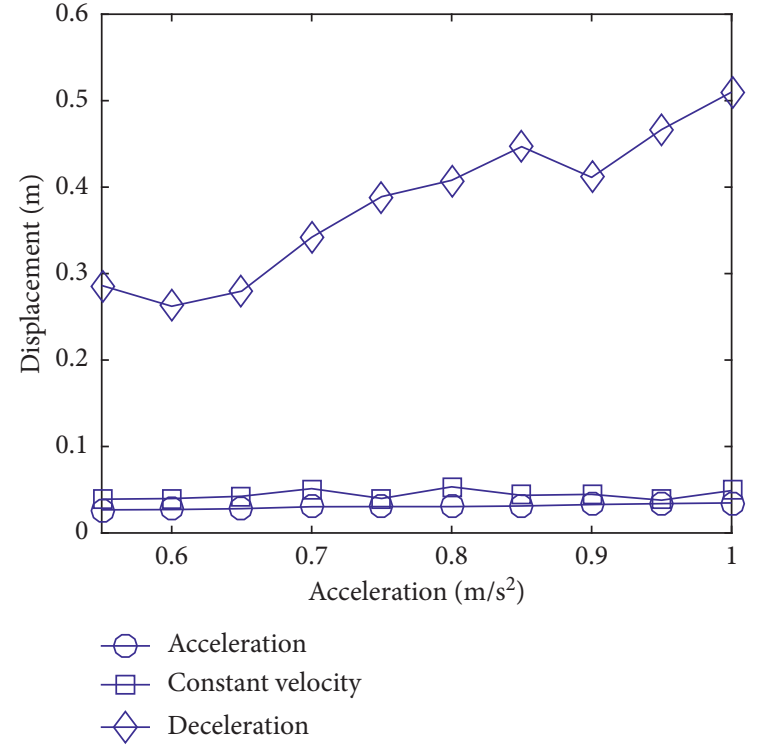

(b)

Figure 10: Maximum axial vibration displacements of the variable-length cable under different accelerations. (a) In lifting the hoist; (b) In lowering the hoist.

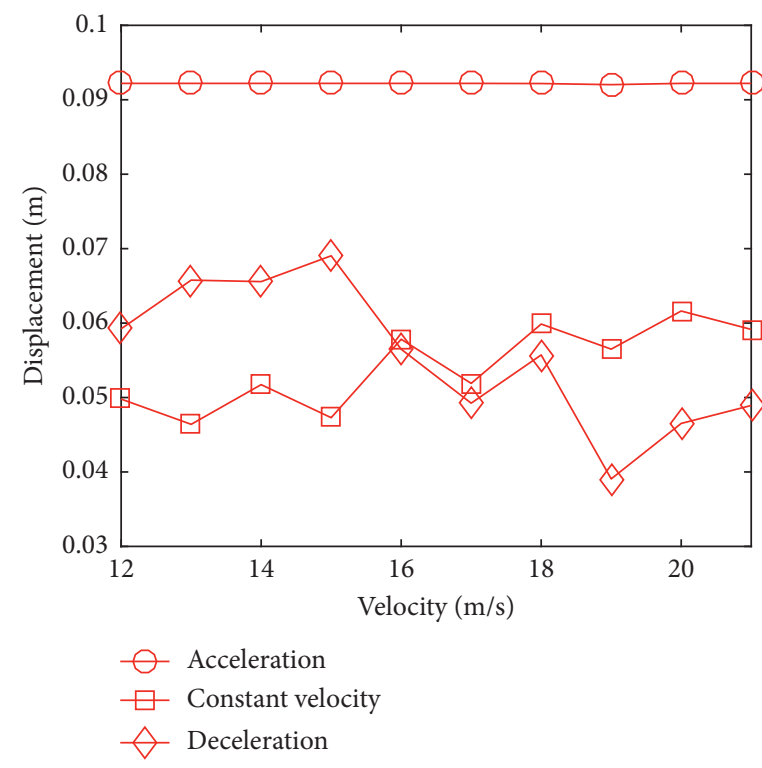

(a)

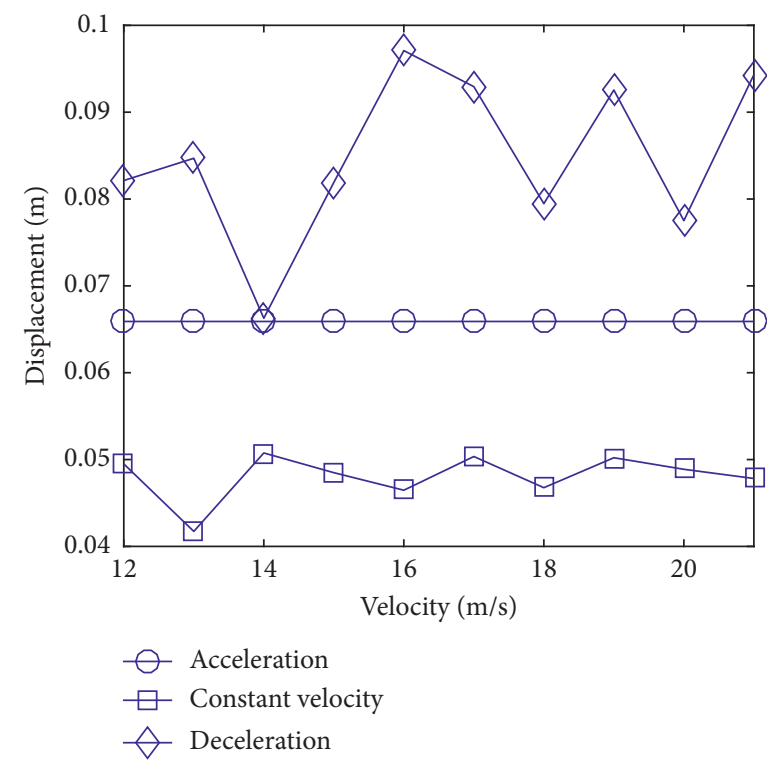

(b)

Figure 11: Maximum axial vibration displacements of the constant-length cable under the different velocities. (a) In lifting the hoist; (b) In lowering the hoist.

different velocities are shown in Figures 11 and 12. In the acceleration phases of coal mine hoist, the axial vibration responses of the hoisting cable are mainly affected by velocities. The velocity change of the coal mine hoist has little influence on axial vibration acceleration of the hoisting rope. Therefore, the maximum displacements of the axial vibration hardly change during the acceleration phase. In the constant speed phases and the deceleration phases, the axial vibration displacements of the hoisting cable are affected by its own tension and velocity. The maximum values of the vibration displacement are nonlinear with velocity. In the lowering process of the coal mine hoist, the axial vibration displacements of the variable-length cable change little in the constant velocity phases. In the lifting or lowering process of the coal mine hoist, the maximum axial vibration displacements of hoisting cable are near the bottom of the shaft.

Remark 1. It can be seen from Figures 5-12 that the load change has the greatest effect on the axial vibration of the 


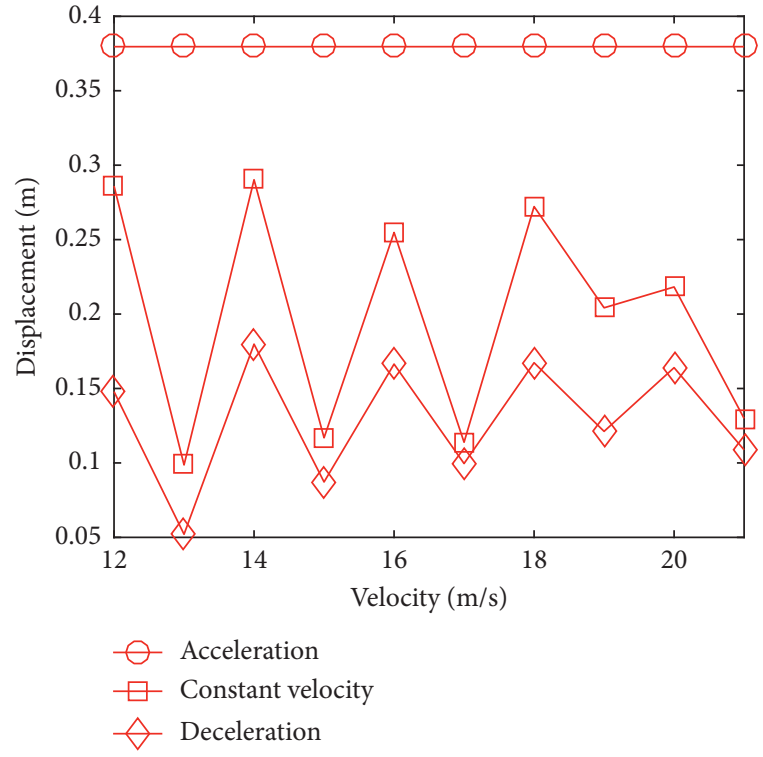

(a)

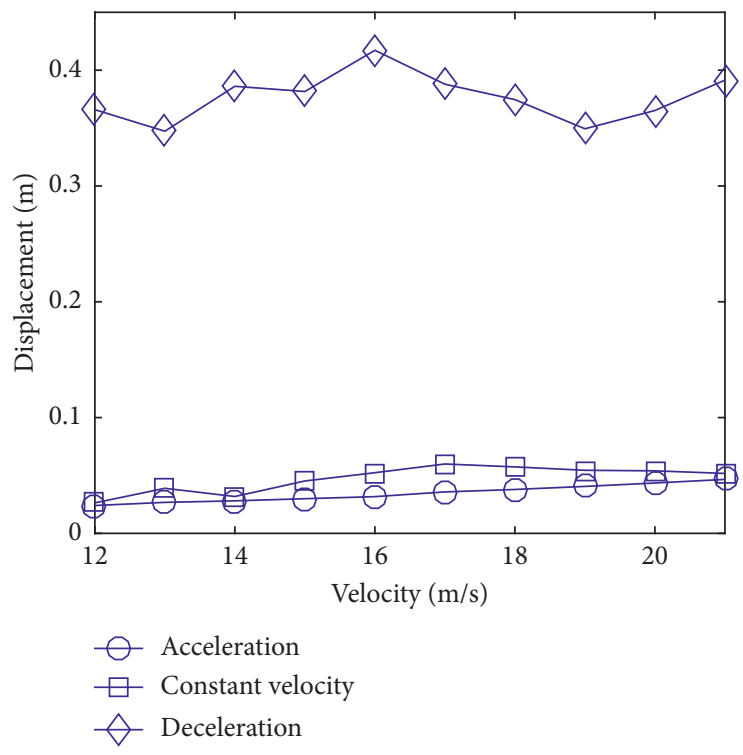

(b)

Figure 12: Maximum axial vibration displacements of the variable-length cable under different velocities. (a) In lifting the hoist. (b) In lowering the hoist.

hoisting cable. The velocity change has the least influence on the axial vibration of the hoisting cable. The influence of depth and acceleration change on the axial vibration of hoisting cable are less than the load change and greater than the speed change. Therefore, during the operation of the coal mine hoist, overload operation should be prohibited. To increase the working efficiency of the coal mine hoist, the running velocity can be appropriately increased. In the acceleration phases, the axial vibration displacements have a linear relationship with the structural parameters. In the deceleration phases, the axial vibration displacements have a nonlinear relationship with the structural parameters. In the constant velocity phases, the different parameters in the lifting or lowering process need to be differently analyzed.

\section{Conclusions}

In this paper, the mathematical equations of the coal mine hoisting system are established by Hamilton's principle. The nonlinear vibration behaviors and key kinematic and structural parameters influences of the hoisting system are analyzed when the coal mine hoist is lifting or lowering. The results are shown as follows:

(1) From acceleration phases to constant velocity phases and from constant velocity phases to deceleration phases, the axial vibration displacements of the hoisting cable changes significantly. The maximum axial vibration displacement of the constant-length cable is an order of magnitude smaller than the variable-length cable. The maximum axial vibration displacement of the hoisting cable in lifting process is similar to the lowering process.

(2) In the acceleration phases, the axial vibration displacements have a linear relationship with the structural parameters. In the deceleration phases, the axial vibration displacements have a nonlinear relationship with the structural parameters. In the constant velocity phases, the different parameters and the hoisting process need to be analyzed.

(3) The load change has the greatest effect on the maximum axial vibration displacements of the hoisting cable. The velocity change has the least influence on the maximum axial vibration displacements of the hoisting cable. The influence of depth and acceleration change on the maximum axial vibration displacements of the hoisting cable are less than the load change and greater than the velocity change. During the operation of the coal mine hoist, the overload operation should be prohibited. To increase the working efficiency of the hoist, the running velocity can be appropriately increased.

\section{Data Availability}

The data used to support the findings of this study are available from the corresponding authors.

\section{Conflicts of Interest}

The authors declare that there are no conflicts of interest regarding the publication of this paper.

\section{Acknowledgments}

This research was funded by the National Natural Science Foundation of China (Grant nos. 51675520, 51975569), and funded by the Priority Academic Program Development of Jiangsu Higher Education Institutions (PAPD), Shandong Provincial Natural Science Foundation (Grant 
no. ZR2017QF011) and Weifang City Science and Technology Development Program (Grant no. 2017GX017).

\section{References}

[1] X. D. Chang, Y. X. Peng, Z. C. Zhu et al., "Breaking failure analysis and finite element simulation of wear-out winding hoist wire rope," Engineering Failure Analysis, vol. 95, pp. 1-17, 2019.

[2] X. D. Chang, Y. X. Peng, Z. C. Zhu et al., "Tribological properties of winding hoisting rope between two layers with different sliding parameters," Advances in Mechanical Engineering, vol. 8, no. 12, pp. 1-14, 2016.

[3] J. N. Yao and X. M. Xiao, "Effect of hoisting load on transverse vibrations of hoisting catenaries in floor type multirope friction mine hoists," Shock and Vibration, vol. 2016, Article ID 8598749, 15 pages, 2016.

[4] J. Yao, X. Xiao, A. Peng, Y. Jiang, and C. Ma, “Assessment of safety for axial fluctuations of head sheaves in mine hoist based on coupled dynamic model," Engineering Failure Analysis, vol. 51, pp. 98-107, 2015.

[5] Y. Guo, D. Zhang, X. Yang, C. Feng, and S. Ge, "Experimental research on effect of wire rope transverse vibration on friction transmission stability in a friction hoisting system," Tribology International, vol. 115, pp. 233-245, 2017.

[6] Y. Wang, G. Cao, and W. T. van Horssen, "Dynamic simulation of a multi-cable driven parallel suspension platform with slack cables," Mechanism and Machine Theory, vol. 126, pp. 329-343, 2018.

[7] L. Yan, G. .H. Cao, N. G. Wang, and J. S. Li, "Lateral stiffness and deflection characteristics of guide cable with multiboundary constraints," Advances in Mechanical Engineering, vol. 9, no. 7, pp. 1-13, 2017.

[8] J. N. Yao, Y. Deng, and X. M. Xiao, "Optimization of hoisting parameters in a multi-rope friction mine hoist based on the multi-source coupled vibration characteristics of hoisting catenaries," Advances in Mechanical Engineering, vol. 9, no. 3, pp. 1-14, 2017.

[9] H. Kimura, H. Ito, Y. Fujita, and T. Nakagawa, "Forced vibration analysis of an elevator rope with both ends moving," Journal of Vibration and Acoustics, vol. 129, no. 4, pp. 471-477, 2007.

[10] R. M. Yani, R. Ghodsi, and E. Darabi, “A closed-form solution for nonlinear oscillation and stability analyses of the elevator cable in a drum drive elevator system experiencing free vibration," Communications in Nonlinear Science and Numerical Simulation, vol. 17, no. 11, pp. 4467-4484, 2012.

[11] G. Rega, "Nonlinear vibrations of suspended cables-part I: modeling and analysis," Applied Mechanics Reviews, vol. 57, no. 6 , pp. $443-478,2004$.

[12] G. Rega, "Nonlinear vibrations of suspended cables-part II: deterministic phenomena," Applied Mechanics Reviews, vol. 57, no. 6, pp. 479-514, 2004.

[13] D.-H. Yang, K.-Y. Kim, M. K. Kwak, and S. Lee, "Dynamic modeling and experiments on the coupled vibrations of building and elevator ropes," Journal of Sound and Vibration, vol. 390, pp. 164-191, 2017.

[14] K.-Y. Chen, M.-S. Huang, and R.-F. Fung, "Dynamic modelling and input-energy comparison for the elevator system," Applied Mathematical Modelling, vol. 38, no. 7-8, pp. 20372050, 2014.

[15] M. Benosman, "Lyapunov-based control of the sway dynamics for elevator ropes," IEEE Transactions on Control Systems Technology, vol. 22, no. 5, pp. 1855-1863, 2014.
[16] H. Askari, D. Younesian, and Z. Saadatnia, "Nonlinear oscillations analysis of the elevator cable in a drum drive elevator system," Advances in Applied Mathematics and Mechanics, vol. 7, no. 1, pp. 43-57, 2015.

[17] S. H. Sandilo and W. T. van Horssen, "On a cascade of autoresonances in an elevator cable system," Nonlinear Dynamics, vol. 80, no. 3, pp. 1613-1630, 2015.

[18] N. V. Gaiko and W. T. van Horssen, "Resonances and vibrations in an elevator cable system due to boundary sway," Journal of Sound and Vibration, vol. 424, pp. 272-292, 2018.

[19] X. Arrasate, S. Kaczmarczyk, G. Almandoz, J. M. Abete, and I. Isasa, "The modelling, simulation and experimental testing of the dynamic responses of an elevator system," Mechanical Systems and Signal Processing, vol. 42, no. 1-2, pp. 258-282, 2014.

[20] W. D. Zhu and H. Ren, "A linear model of stationary elevator traveling and compensation cables," Journal of Sound and Vibration, vol. 332, no. 12, pp. 3086-3097, 2013.

[21] W. D. Zhu and L. J. Teppo, "Design and analysis of a scaled model of a high-rise, high-speed elevator," Journal of Sound and Vibration, vol. 264, no. 3, pp. 707-731, 2003.

[22] Y. Liu, Y. Kao, H. R. Karimi, and Z. Gao, "Input-to-state stability for discrete-time nonlinear switched singular systems," Information Sciences, vol. 358-359, pp. 18-28, 2016.

[23] Y. Liu, Y. Kao, S. Gu, and H. R. Karimi, "Soft variable structure controller design for singular systems," Journal of the Franklin Institute, vol. 352, no. 4, pp. 1613-1626, 2015.

[24] L.-Q. Chen, N.-H. Zhang, and J. W. Zu, "The regular and chaotic vibrations of an axially moving viscoelastic string based on fourth order Galerkin truncation," Journal of Sound and Vibration, vol. 261, no. 4, pp. 764-773, 2003. 


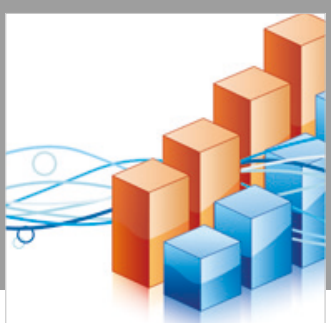

Advances in

Operations Research

\section{-n-m}
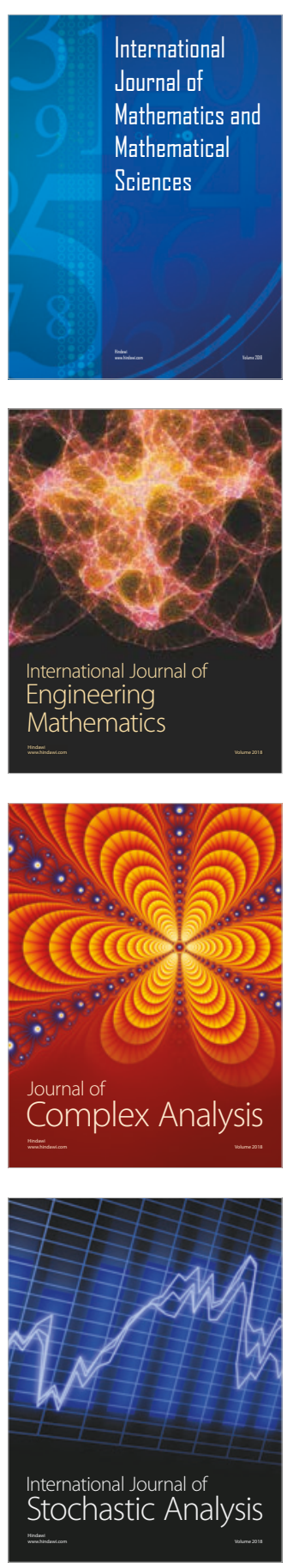
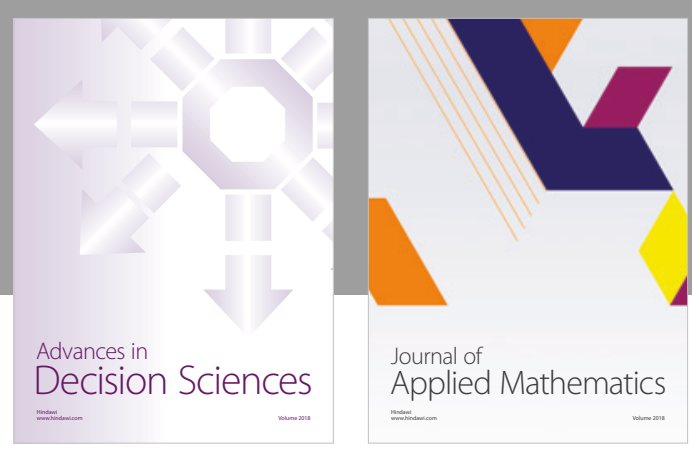

Journal of

Applied Mathematics
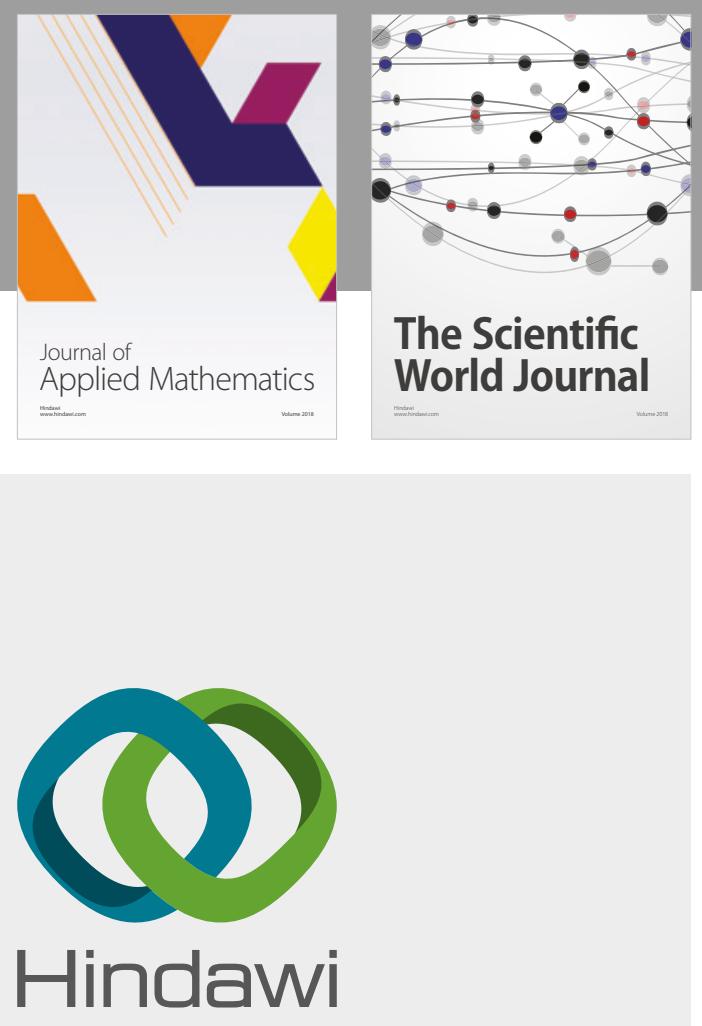

Submit your manuscripts at

www.hindawi.com

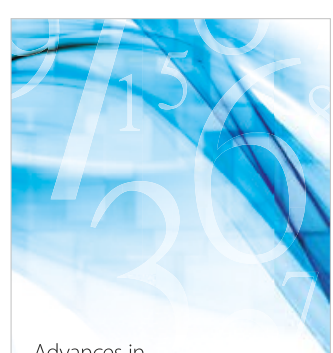

Advances in
Numerical Analysis
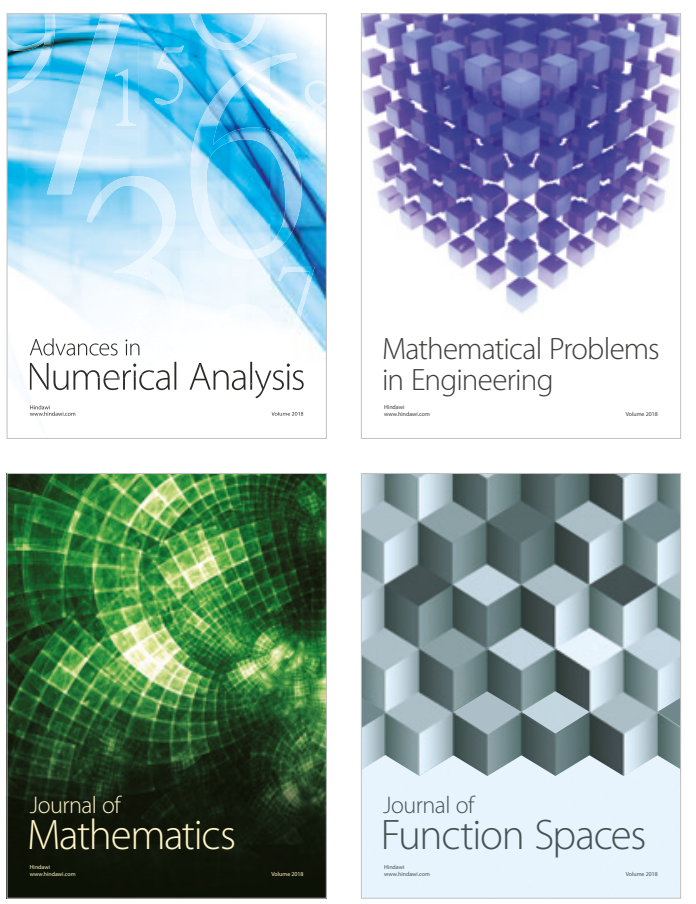

Mathematical Problems in Engineering

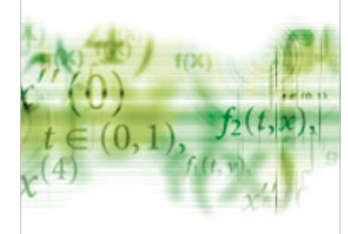

International Journal of

Differential Equations

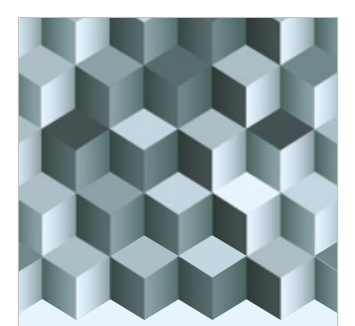

Journal of

Function Spaces

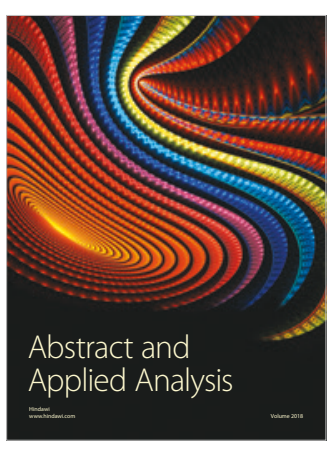

The Scientific

World Journal

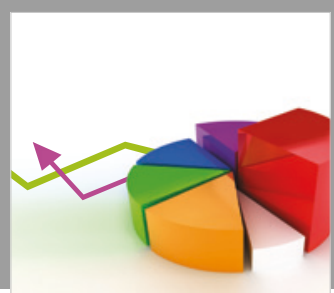

Journal of

Probability and Statistics
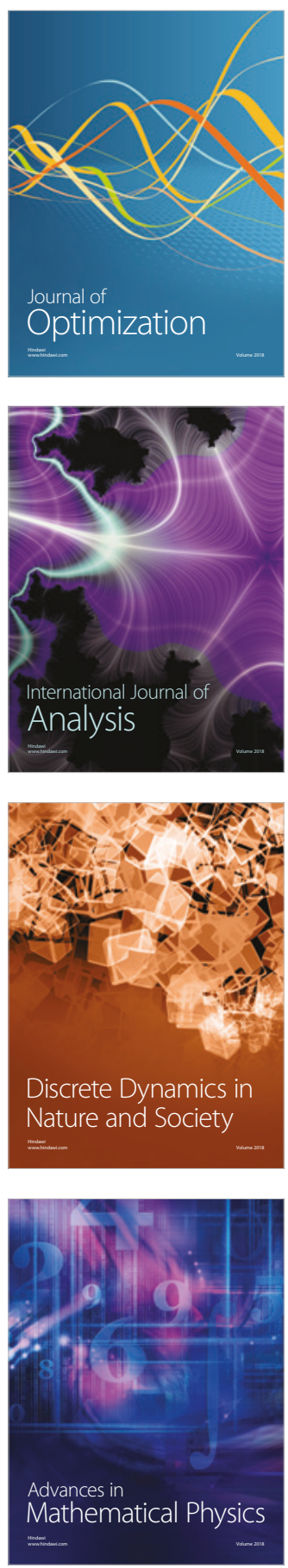